\title{
A PRODUÇÃO DE IMAGINÁRIOS SOCIAIS SOBRE A ESCOLA E SEUS EFEITOS NA FORMAÇÃO INICIAL DE PROFESSORES DE EDUCAÇÃO FÍSICA
}

\author{
GRAD. BRUNO VASCONCELLOS SILVA*
}

Licenciado em Educação Física pela UFES e Professor da Rede Pública Municipal de Ensino de

Cariacica - ES (Espírito Santo - Brasil)

e-mail: bvasconcellos1983@hotmail.com

\section{MS. FRANCISCO EDUARDO CAPARRÓZ}

Mestre em Educação pela PUC-SP e Professor Adjunto do Centro de Educação Física e Desportos (CEFD) da Universidade Federal do Espírito Santo (Espírito Santo - Brasil)

e-mail: caparroz.vix@gmail.com

\section{MS. UEBERSON RIBEIRO ALMEIDA}

Mestre em Educação Física pela UFES e Membro do Núcleo de Estudos e Pesquisas em Subjetividade e Política - NEPESP/CCHN/UFES (Espírito Santo - Brasil)

e-mail: uebersonribeiro@terra.com.br

\begin{abstract}
RESUMO
Trata-se do desdobramento de uma pesquisa realizada com alunos de licenciatura em Educação Física. Busca, em um trabalho etnográfico, compreender e analisar o imaginário social desses discentes acerca de suas experiências escolares e de formação inicial. Por meio do trabalho empírico problematizado com base na produção teórica sobre a temática, bem como de outros dados que possibilitaram triangulações, identifica elementos e esquemas que se constroem ao longo do processo de escolarização dos futuros professores. Essas estruturas se expressam (com força considerável, certo conformismo e conservadorismo) no imaginário dos alunos em formação, o que coloca desafios e possibilidades para o processo de formação crítica de professores de Educação Física para atuarem na escola.
\end{abstract}

PALAVRAS-CHAVE: Educação Física escolar; imaginário social; escolarização; formação inicial.

* Todos os autores do estudo são membros do Laboratório de Estudos em Educação Física - LESEF/CEFD/ UFES. 


\section{INTRODUÇÃO}

Este estudo faz parte de uma investigação realizada na disciplina Educação Física Escolar III, componente curricular do curso de formação inicial de professores de Educação Física do Centro de Educação Física e Desportos, da Universidade Federal do Espírito Santo. Priorizamos, para este espaço, as facetas que compõem a trama de construção do imaginário social dos alunos no que diz respeito à sua escolarização e seus efeitos no processo de ensino-aprendizagem na formação inicial acadêmica.

Trata-se de um trabalho qualitativo e de natureza predominantemente etnográfica, do qual participaram 25 discentes que estavam cursando o oitavo período do Curso de Licenciatura Plena em Educação Física, matriculados na disciplina Educação Física Escolar III no primeiro semestre do ano de 2006. Vale dizer que a opção pela realização deste estudo na referida disciplina articula-se à pesquisa "tronco" intitulada "Formação Inicial de Professores de Educação Física: (Re)construindo a Prática Pedagógica na Disciplina Educação Física Escolar-III do CEFD-UFES", a qual está alicerçada em pressupostos da pesquisa-ação e visa a colocar a prática pedagógica do professor universitário em questão, em uma perspectiva crítico-colaborativa que busca reconstruir e potencializar a prática pedagógica na formação inicial de professores de Educação Física.

A compreensão do imaginário social dos futuros professores adquire relevância, tanto no que se refere a colocar em questão os currículos da formação inicial de professores de Educação Física, quanto a pensar em práticas pedagógicas - por parte dos professores formadores de professores - que possam ultrapassar o mero exercício conteudista, levando em consideração as combinações entre símbolos e significados que se expressam em crenças, anseios e desejos dos discentes.

Fundamentamo-nos na perspectiva de Castoriadis (1982), para o qual o imaginário social consiste na ligação entre símbolos e significados formando uma rede de sentidos que resultam da atividade da razão e da imaginação. Nessa rede de sentidos, surgem elementos fundamentais para o processo de simbolização que são: crenças, fantasias, desejos, necessidades, sonhos, interesses, raciocínios e intuições. Essas redes de sentidos predominam sobre diversos aspectos da conduta coletiva, na medida em que valores, normas e interdições, como códigos coletivos, são internalizados/apropriados pelos agentes sociais, visto que tais códigos exprimem necessidades, interesses e expectativas conscientes e inconscientes desses agentes e, ainda, expressam desejos e fantasias que conferem ao objeto uma dupla realidade: a real e a imaginária. Como um amálgama, o imaginário social institui, histórica e culturalmente, o conjunto das interpretações, das experiências individuais vividas e construídas coletivamente. 
Portanto, buscamos compreender, como se constituem as ligações entre símbolos e significados dos discentes em formação inicial, tendo por base suas experiências no processo de escolarização. No decorrer da pesquisa, as problematizações produzidas possibilitaram a percepção de nuanças que emergem no imaginário dos discentes em decorrência de suas experiências a respeito da escola, uma vez que não era possível separar de forma exclusiva suas percepções acerca dos seus processos de escolarização de suas experiências acerca da escola, tanto no que tange ao estudo das diversas temáticas a respeito desta, como também às suas vivências no âmbito escolar como discentes de um curso de formação inicial de professores (estágios, estudos in loco fomentados por diferentes disciplinas do curso, etc.). Ainda que nosso interesse central, aqui, recaia no curso da composição do imaginário social dos discentes (futuros docentes) no concernente à sua escolarização e seus efeitos na relação ensino-aprendizagem no engendrar da formação inicial, era impossível não considerar outros elementos (que muitas vezes estavam implícitos/inconscientes para os próprios discentes) da trajetória de cada um dos sujeitos pesquisados, pois não poderíamos desconsiderar que os mesmos já eram alunos finalistas de um curso de formação inicial de professores. Valemo-nos, por exemplo, da música "Estudo Errado"' de Gabriel, O Pensador, para refletirmos tanto com os referidos discentes no decorrer da disciplina EFE III, como também para elaboração deste artigo acerca do processo de escolarização que se apresenta como obstáculo à formação crítica de professores de Educação Física Escolar.

\section{METODOLOGIA}

Para compreendermos o imaginário social dos discentes e os movimentos que nele se operam na formação inicial de professores, realizamos um estudo de caso do tipo etnográfico durante o primeiro semestre letivo de 2006. Em um estudo de caso etnográfico há problemas que necessitam de uma microinvestigação e, relacionando o estudo de caso com a etnografia, pode-se denominar de "microetnografia" as investigações que focalizam aspectos muitos específicos de uma realidade maior (KREUSBURG MOLINA, 1999). A "microetnografia" é uma forma eficaz de investigar as interações de sala de aula, os métodos de ensino, as práticas de avaliação, o trabalho docente em geral (ANDRÉ, 1995).

O acesso ao campo ocorreu sem conflitos, inclusive quando se tratou dos aspectos formais no que diz respeito ao termo de consentimento livre esclarecido

I. Cf. Música "Estudo Errado" em GABRIEL, O PENSADOR, 1999. Dialogaremos com a letra dessa música ao longo do texto e destacaremos os trechos com aspas toda vez que fizermos citação direta da obra. 
entregue aos alunos, o qual foi assinado por todos nos autorizando a realizar a pesquisa. Grande parte dos alunos já nos conhecia em razão do convívio nas festas da universidade, nos Jogos Internos do Centro de Educação Física e Desportos (JICEF) e no próprio cotidiano do CEFD. As relações de confiança e amizade préestabelecida com os discentes foram "[...] capazes de mediar encontros, viabilizar o acesso, assim como trabalhar os possíveis choques culturais que podem existir nos primeiros contatos" (MACEDO, 2000, p. I49). Corroborando essa proposição, Bogdan e Biklen (1994, p. 123) sugerem que, aos primeiros dias no campo de investigação, o pesquisador "[...] tente arranjar alguém que o apresente". Isso pode facilitar, sobremaneira, sua entrada no ambiente de pesquisa.

Durante o desenvolvimento do estudo, buscamos ser o mais frequente possível no campo de pesquisa. Acompanhamos as atividades acadêmicas desempenhadas pelos estudantes e participamos (auxiliando e problematizando) das reuniões de trabalho dos grupos de alunos.

Nossa entrada no campo ocorreu no dia 13 de março de 2006 e permanecemos até o dia 10 de julho do mesmo ano. Durante esse período, estivemos junto dos discentes da disciplina todas as segundas-feiras das I3h00min às I 7h00min. Foram realizados 15 encontros/aulas durante esse período, totalizando 60 horas/ aulas, além dos encontros promovidos pelas entrevistas, pelos corredores e cantina do CEFD e via internet (Orkut e e-mails).

Fizemos observação participante, entrevistas semiestruturadas e criamos um diário de campo. O diário nos permitiu registrar informações produzidas no cotidiano da sala de aula, bem como a elaboração de notas de campo. Nesse sentido, Bogdan e Biklen (1994) postulam que notas de campo são relatos escritos pelo pesquisador sobre o que ele ouve, vê, vivencia e pensa no decorrer da pesquisa. Para que a observação seja bem sucedida, as notas de campo devem ser detalhadas, precisas e extensivas a todos os dados recolhidos durante o estudo. Realizamos observações durante o processo de ensino aprendizagem da disciplina: as salas de aula, também fora do momento de aula, na cantina, no pátio externo, nas conversas informais nos corredores da universidade, na biblioteca e nas diferentes ocasiões de encontro com os discentes como reuniões de pequenos grupos.

Em algumas aulas utilizamos um gravador de áudio como estratégia para auxiliar na produção dos dados. Percebemos, no entanto, que alguns alunos se mostraram um pouco tímidos, no início, com a presença do gravador. Então, colocamos em análise junto com discentes, a permanência ou não do aparelho nas aulas. Relembramos aos discentes que eles não seriam identificados nas transcrições dos áudios, que poderiam desligar o gravador quando necessário, bem como poderiam acessar e suprimir as gravações que viessem a constrangê-los. Após essa conversa e 
a consequente codecisão pela permanência do gravador, os encontros subsequentes revelaram que o gravador não incomodava mais o ambiente da aula.

Para realizar as notas de campo durante o processo de investigação sempre levávamos um caderno para fazer os registros necessários e, em seguida, redigíamos essas notas como diário de campo diretamente no computador. De acordo com Macedo (2000), o diário de campo é um aprofundamento reflexivo sobre as experiências vividas no campo de pesquisa e no campo de sua própria elaboração intelectual com o objetivo de compreender o contexto do trabalho da investigação científica e colocar novos problemas. Nas notas de campo buscamos realizar registros como: conversas dentro e fora de sala de aula que estavam relacionadas com o processo de ensino-aprendizagem da disciplina, alguns acontecimentos interessantes, relatávamos dúvidas, sentimentos e reflexões sobre o que estava sendo discutido. Além disso, aproveitamos boa parte desses dados para elaborar as entrevistas realizadas com os discentes.

As entrevistas foram gravadas e transcritas com o consentimento dos entrevistados. Todos os discentes entrevistados tiveram acesso à transcrição e operaram as revisões necessárias. Entrevistamos oito alunos da disciplina Educação Física Escolar III do primeiro semestre de 2006, totalizando dezesseis entrevistas semiestruturadas, duas com cada aluno, somando o total de onze horas e quinze minutos de entrevistas. Todos os alunos que participaram das entrevistas se colocaram de forma voluntária e deixamos claro que garantiríamos o anonimato de todos.

Utilizamos a entrevista semiestruturada, a qual corresponde uma sequência de perguntas abertas feitas verbalmente em uma ordem previamente estabelecida, podendo ocorrer no decorrer da entrevista, o acréscimo de outras perguntas pelo entrevistador e pelos entrevistados (LAVILLE; DIONNE, 1999).

Foram realizadas duas entrevistas com cada discente devido à grande quantidade de perguntas que estipulamos para o roteiro de entrevistas. Com isso, dividimos a entrevista em quatro blocos nos quais as perguntas dos blocos I e II foram realizadas na primeira sessão de entrevistas, intitulados respectivamente de: "Quem é o entrevistado/De quem é essa voz?" E, "Expectativas quanto ao curso de Educação Física/Formação acadêmica". As perguntas dos blocos III e IV estavam na segunda sessão de entrevistas intitulados respectivamente de "Educação Física Escolar" e, o outro de "Processo de ensino-aprendizagem na disciplina Educação Física Escolar III". Realizamos um total de trinta e nove perguntas nas duas sessões de entrevistas sendo que o bloco I continha cinco, o bloco II doze, o bloco III seis e o bloco IV dezesseis perguntas.

No processo de análise operamos triangulações envolvendo os dados produzidos nas entrevistas, notas de campo e referências bibliográficas. Embora o 
montante e a variedade de dados produzidos sejam extensos, privilegiamos para o texto que ora apresentamos as análises derivadas dessa triangulação, uma vez que a principal preocupação no estudo de caso do tipo etnográfico é com o significado que as pessoas ou grupos estudados atribuem às ações, eventos e às realidades que a cercam e, devido à complexidade dessa tarefa, no decorrer da pesquisa, segundo André (2005), comumente os pesquisadores se utilizam de técnicas de produção de dados como observação participante, entrevistas, análises de documentos, questionários, testes, mapas conceituais, dados estatísticos e outros. Contudo, os três primeiros são os mais utilizados.

Ressaltamos que os dados produzidos solicitaram o diálogo com referências - não apenas acadêmicas - não previstas antes do contato com o campo, como a Música "Estudo Errado" de Gabriel "O Pensador", as discussões específicas sobre "educação bancária" e a relação entre teoria e prática. Ou seja, a produção de dados também demandou problematizações capazes de auxiliar no desenvolvimento de análises sobre a complexidade que envolve a constituição de imaginários sociais de alunos do curso de formação inicial de professores de Educação Física.

\section{EXPERIÊNCIAS DOS DISCENTES EM RELAÇÃO À ESCOLA}

Por que é tão difícil romper com modelos de formação inicial de professores fundados sobre os pilares de uma razão técnico-instrumental? Por que grande parte dos discentes dos cursos de formação inicial de professores de Educação Física preferem trabalhar em espaços diferentes dos da escola? Quais símbolos e significados os futuros professores trazem de seus processos de escolarização acerca da escola e da Educação Física para a formação inicial de professores? Como os códigos internalizados nos processos de escolarização emergem e interferem no processo de formação inicial?

No que diz respeito ao processo civilizatório via educação, Pérez Gómez (1998) afirma que à escola é atribuído o papel, entre outros, de transmitir para as outras gerações os conhecimentos adquiridos ao longo da história da humanidade desenvolvendo, assim, o processo de socialização das novas gerações. Contudo, há outras instâncias que também cumprem esse papel, que são as famílias, os grupos sociais e os meios de comunicação.

Para esse autor, há dois objetivos para a socialização dos alunos na escola: o primeiro é prepará-los para o mundo do trabalho e para isso é importante o desenvolvimento, nas novas gerações, não apenas de conhecimentos, ideias, habilidades e capacidades formais, mas também de formações de disposições, atitudes, interesses 
e pautas de comportamentos; o segundo objetivo é a formação de cidadãos para intervenção na vida pública de modo que possam transformar a cultura hegemônica imposta (PÉREZ GÓMEZ, 1998).

No entanto, tendo em vista as lembranças das experiências vividas pelos discentes investigados, por vezes, também observamos um processo de escolarização que busca transmitir uma ideologia cujos símbolos indicam sentidos de uma lógica meritocrática e individualista expressa por elementos como desigualdade "natural" de resultados em função de capacidades e esforços individuais (GENTILI, I996; SACRISTÁN, 1996; SILVA, 2002).

Identificamos, nas memórias dos discentes, que tais símbolos exprimem significados como: uma escola meramente funcionalista, a necessidade de fazer uma coisa para que receba outra em troca e de ter que mostrar resultados. Segundo um dos discentes, por isso foi preciso "Estudar pra ser 'alguém' na vida [...] eu tinha que estudar se eu quisesse ser alguém futuramente" (LUIGI). ${ }^{2}$

A característica profunda do fenômeno simbólico é a sua indeterminação relativa que pode ser indicada pelo fenômeno da "sobredeterminação dos símbolos" - vários significados podem ser ligados ao mesmo símbolo (CASTORIADIS, 1982). Os símbolos expressos pelos discentes acerca do que foi a escola, em parte, permite-nos elaborar uma combinação composta por: individualismo, competitividade, falta de solidariedade, igualdade formal de oportunidades e desigualdade "natural" de resultados em função de capacidades e esforços individuais. Identificamos, também, que, na trama do imaginário, esses símbolos se relacionam com os significados expressos pelos futuros professores, como: escola meramente funcionalista, bom aluno, e também da busca incessante pelos resultados. Isso, no caldeirão denominado por Castoriadis ( 1982) como fenômeno da "simbolização do sentido", é o que ocorre, quando o mesmo significado é carregado por vários símbolos (CASTORIADIS, I982).

Tendo como base as experiências dos discentes em seu processo de escolarização, elaboramos um esquema de forma a expressar a compreensão de possíveis ligações que podem ocorrer entre símbolos e significados que compõem uma importante faceta do imaginário dos futuros professores de Educação Física.

2. Utilizamos pseudônimos para nos referir aos discentes que participaram da pesquisa. 


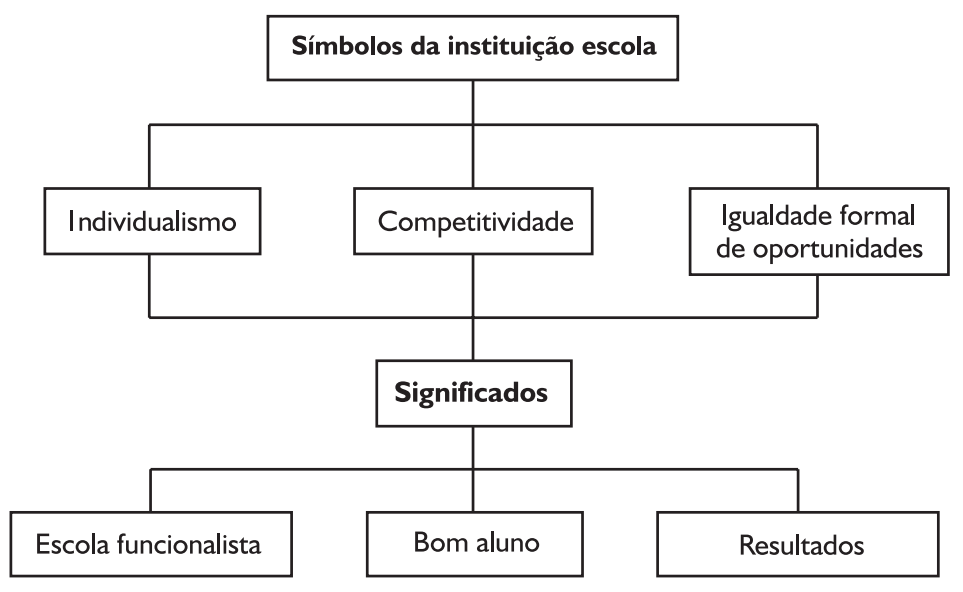

Esquema I. Processo de escolarização dos discentes

Esse esquema foi uma forma de explicitar a rede de sentidos que pode se formar a partir das ligações que ocorrem entre símbolos e significados. Tais ligações não necessariamente se ligam de forma direta. Essa rede de sentidos influencia vários aspectos de conduta coletiva, na medida em que valores, crenças, normas e interdições, como códigos coletivos, são internalizados/apropriados pelos agentes sociais. Esses códigos exprimem necessidades, interesses, desejos, as expectativas conscientes e inconscientes desses agentes (CASTORIADIS, 1982).

Com base nesse autor, os símbolos da "competitividade" e "igualdade formal de oportunidades" ligados ao significado de "busca por resultados" podem ser identificados na fala do aluno Godines: "Eu tinha que tirar nota boa pra agradar meu pai. Se o boletim tivesse nota boa era o que interessava; se eu aprendi ou não, não interessava". Nesse caso, os símbolos e significados foram internalizados/ apropriados pelos discentes tanto no processo de escolarização, quanto nas famílias. Nessa concepção de escola, o bom aluno é aquele que senta "lá na frente", tira as melhores notas e faz todas as tarefas. Dessa forma, o aluno e as instituições (escola e família) mais se preocupam com as notas altas do que com o aprendizado. Assim, podemos fazer uma analogia com o refrão da música "Estudo Errado" de Gabriel "O Pensador": "Manhê! Tirei um dez na prova. Me dei bem tirei um cem e quero ver quem me reprova. Decorei toda lição. Não errei nenhuma questão. Não aprendi nada de bom. Mas tirei dez (Boa filhão)".

O símbolo da "competitividade" pode ser ligado ao significado de "escola funcionalista". Essa ligação pode ser identificada na entrevista, pela fala de um dos alunos: 
[...] minha mãe que chegou pra mim e disse: 'Seu tio passou na Escola Técnica [CEFETES] e entrou na Vale [Companhia Vale do Rio Doce]! Tá bem na Vale! Tá ganhando bem!'. Então, eu acho que escola técnica é um negócio legal! (GODINES).

A escola, como preparação exclusivamente para o mercado de trabalho, é o "desejo" da mãe, que concebe a educação como um "bom negócio". Para Lefebvre ( $|99|$ ), a produção de sentidos que circulam na sociedade permitem a regulação de comportamentos, bem como a identificação e distribuição de papéis sociais. Dessa forma, isso é vivenciado de tal modo pelos agentes sociais que passa a funcionar para o grupo o sentido daquilo que é verdadeiro. Assim, investir na educação dos filhos gera a promessa "coerente e verdadeira" para as famílias e para o estudante do rendimento de tudo aquilo que foi nele depositado, "um negócio legal!”. Contudo, é necessário colocar em questão as bases sobre as quais a produção de imaginários sociais se fundamenta e se legitima, pois essa passa por sistemas simbólicos, pelos quais as relações hierárquicas da sociedade podem ser apreendidas mediante cotidianos ritualizados, fazendo "crer" que elas são naturais.

Ao continuar a análise, podemos fazer uma analogia do que expressam os discentes em algumas de suas lembranças da escola com o que Gentili (1996, p. 3 I) chama de Mcdonaldização da escola.

[...] se o sistema escolar tem que se configurar como mercado educacional, as escolas devem definir estratégias competitivas para atuar em tais mercados, conquistando nichos que respondam de forma específica à diversidade existente nas demandas de consumo por educação. Mcdonaldizar a escola supõe pensá-la como uma instituição flexível que deve reagir aos estímulos (os sinais) emitidos por um mercado educacional altamente competitivo.

Por sua vez, o significado de "bom aluno" pode ser ligado aos três símbolos expostos no Esquema I, pois a lógica competitiva é promovida por um sistema de prêmios e castigos baseada na meritocracia e no esforço individual (GENTILI, 1996; FRIGOTTO, 1996). Haja vista a fala da aluna Florinda, "Sempre fui boa aluna, sempre fui 'CDF', por exemplo, ele [o pai] queria nota dez, e eu me matava pra tirar, e sei lá, ganhava dez reais".

Outros alunos exprimem significados ambivalentes ao relatarem que não gostavam de ir à escola, ao mesmo tempo em que a escola era entendida como obrigação, e não sabiam explicar por que iam à escola, mas afirmavam encontrar, nessa instituição, prazer, devido aos amigos e ao divertimento: "[...] você é obrigado a ir, mas, ao mesmo tempo, você gosta de ir" (Entrevista, KIKO). E nesse intrigante paradoxo, o importante é perceber que o "gostar" da escola está ligado ao mundo de relações e de experiências positivas que esta instituição produz ao 
forjar subjetividades. Experiências sensíveis que os alunos "carregam" por toda a vida e que podem se tornar importantes dispositivos pedagógicos de análise nos processos de formação inicial de professores de Educação Física. Defendemos que é necessário resgatar essas experiências de escolarização para compreendermos, na formação inicial, as tramas que nos constitui como docentes e a complexidade que envolve a vida na escola. Complexidade que podemos observar na ambivalência da fala do aluno:

A escola pra mim era obrigação. Tinha que estar na escola, tinha prazer de ir à escola sim, porque era um divertimento, porque tinha amigos, conseguia fazer as aulas. Dentro das aulas aprendi muito, gostava muito quando me envolvia com as pessoas, mas eu via escola em primeiro momento como obrigação, sair de casa, colocar o uniforme, ir pra lá e voltar (Entrevista, GODINES).

Os símbolos e significados expressos nas lembranças dos discentes acerca do que foi a escola coadunam com a situação de alunos que não entendem o motivo de ir à escola. Ao analisar a escolarização por meio do paradoxo presente na afirmação do aluno, podemos também afirmar que a escola é esse "lugar" da produção de relações positivas específicas que permitem aos alunos experimentar o mundo de modos diferentes dos da família e de outras instituições produtoras de imaginários. As crianças são obrigadas a compartilhar valores coletivos e civilizatórios por meio do processo de escolarização. Mas, embora "obrigados", os encontros que a escola possibilita permite deslocamentos nos modos de pensar e de se relacionar; é a oportunidade de desnaturalizar a vida e a própria história. Na mesma linha de pensamento, "ver a escola como obrigação" também nos leva a inferir que os métodos formais de ensino necessitam dialogar com a vida nas comunidades, nos entornos da escola e com os problemas que são caros aos alunos. Quando a escola trata o ensino com base em uma lógica de educação "bancária", os alunos são levados apenas a incorporar modelos e valores heterodeterminados, sem espaço para reflexão e para produção de autonomia. Processos de ensino que não auxiliem os alunos a transformarem a "obrigação" em "prazer" de estudar tendem a produzir um "estudo errado" como expresso no refrão da música de Gabriel "O Pensador": "Quase tudo que aprendi, amanhã eu já esqueci/Decorei, copiei, memorizei, mas não entendi/Quase tudo que aprendi, amanhã eu já esqueci/Decorei memorizei, mas não aprendi".

Nesse sentido, podemos interpelar: Como os processos de escolarização interferem na formação inicial de professores (de Educação Física)? E como isso interferiu/interfere na adesão e resistência dos alunos em formação inicial por perspectivas críticas de ensino/formação? 
O imaginário social possui significados articulados com o que a sociedade atual impõe ao mundo, a si mesma e as suas necessidades. A característica essencial da linguagem é a sua relação com tais significados, e esses não se reduzem a uma significação fixa e determinada, mas estão sempre abertos a transformações (CASTORIADIS, 1982).

Identificamos, também, os símbolos e significados que hoje, no plano do imaginário, significa a escola para os discentes da disciplina EFE III como alunos finalistas de um curso de formação de professores de Educação Física.

Observamos, nos dados produzidos, o fenômeno da "sobredeterminação dos símbolos" pelo qual os discentes exprimem símbolos da escola, como: socialização, formação do cidadãos e formação da personalidade. Esses símbolos estão ligados a vários significados, como: transmissão dos conhecimentos, orientação para a vida e questões de valores sociais e valores morais. É o que expressa a aluna Madalena: "A escola é imprescindível na transmissão de conhecimentos para ajudar no processo de socialização, coletivização, democratização, convivência com outros numa sala totalmente heterogênea (Diário de campo, MADALENA).

A partir de nossa análise mais ampliada e da imersão nos dados, elaboramos um esquema que se refere à visão de escola dos discentes como alunos finalistas do Curso de Educação Física.

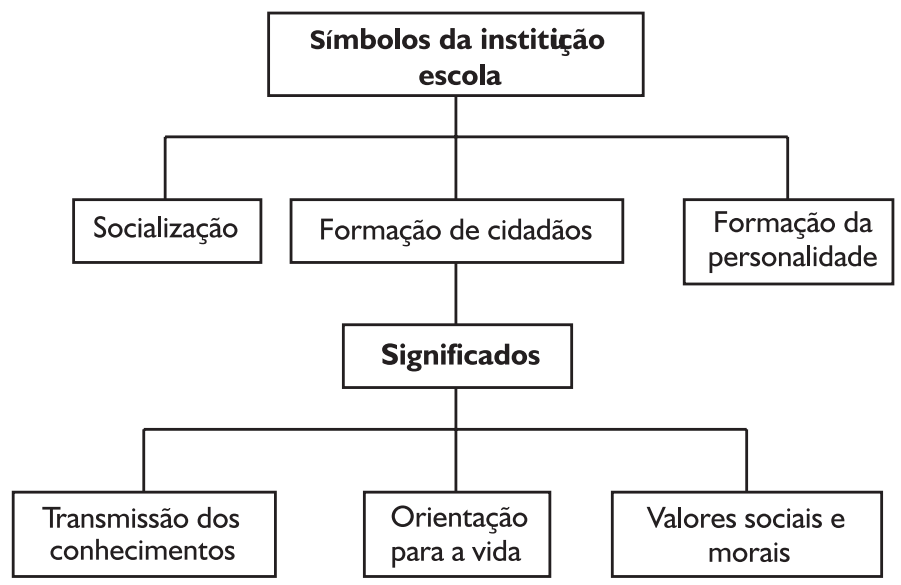

Esquema 2. Visão de escola para discentes finalistas do curso de formação de professores de Educação Física

Essa rede de sentidos - ligações entre símbolos e significados - apresentada no Esquema 2, traz códigos coletivos que foram internalizados/apropriados em 
seu processo de formação inicial, bem como em seu processo de escolarização. O imaginário social, como postula Castoriadis ( 1982), é uma espécie de "magma", uma instituição do pensamento "relativamente estável" e sensível aos atritos e às rupturas no confronto discursivo com "outros mundos". Nesse sentido, podemos notar alguns deslocamentos acerca da visão dos futuros professores de Educação Física sobre a escola em relação às lembranças que os mesmos possuíam sobre seu processo de escolarização apresentados no Esquema I.

Nos jogos de força que constituem formas no imaginário, ao analisar os dados ${ }^{3}$ que permitiram construir o Esquema 2, notamos que o símbolo da "socialização" pode ser ligado ao significado de "transmissão de conhecimentos". Tal ligação foi identificada na fala da aluna Madalena: "A escola é imprescindível na transmissão de conhecimentos para ajudar no processo de socialização". Já os símbolos de "socialização" e "formação de cidadãos" podem ser ligados aos significados de "valores sociais e morais" e "orientação para vida", pois "A escola é importante, principalmente com essas questões dos valores morais, valores sociais" (Entrevista, GODINES). Os valores caracterizam e configuram as relações nas sociedades, por isso é importante tratá-los pedagogicamente na escola:

A educação está convocada para enraizar esses valores na consciência dos alunos e perpassá-los pelo conhecimento e por todas as atividades escolares. Nesse sentido é possível estabelecer o que significa realmente educar em sua profundidade. Significa aquele aprendizado que se incorpora na medida em que se vai construindo a própria vida, a própria existência em solidariedade. É um homem ajudando o outro homem, um indivíduo ajudando outro indivíduo a poder se inserir, a poder produzir, a poder a fazer a própria existência. Assim supera-se a ideia de vencer na vida, como se ela só pudesse se realizar pela derrota de outro (SILVA, 2002, p. 42).

E, ainda, os símbolos de "formação de cidadãos" e "formação da personalidade" podem ser ligados aos três significados expostos no Esquema 2. De acordo com a aluna Jane, a escola "Tem importância no aspecto da formação abrindo os horizontes em relação à obtenção do conhecimento sobre o mundo e sobre as outras pessoas". Nessa esteira, Freire (1996) postula que devemos incitar a capacidade crítica e a curiosidade do educando, portanto o docente não deve apenas ensinar os conteúdos, mas ensinar a pensar. Corroborando esse pensamento, Silva (2002) afirma que devemos superar o significado de cidadania como meramente cívico de cumprimento dos deveres da ordem estabelecida:

3. Para construção dos esquemas, utilizamos dados dos diários de campo, das entrevistas e das fontes teóricas. Como os esquemas não são representações, mas possíveis relações entre símbolos e significados, valorizamos os dados das entrevistas para analisar as tramas do imaginário relativas às experiências escolares dos futuros docentes. 
Aos alunos, como cidadãos, é exigido o alargamento de suas relações pelo rompimento do universo limitado pelo âmbito da escola para situá-lo no todo social. Não há como ignorar, no recinto da escola, as distorções de um sistema de sociedade que impede uma grande parcela da população de se apropriar dos bens materiais e culturais da população social, de assumir o seu papel de sujeito tanto do seu processo de produção como do processo de construção social da vida, no exercício fundamental da cidadania (SILVA, 2002, p. 43).

Entretanto, esses símbolos e significados não estão apenas no plano do pensamento abstrato sobre a transformação da realidade, "[...] não são alheios às relações de poder e às relações de classe presentes na sociedade. Pelo contrário, são mediações de sua explicitação ou de seu mascaramento" (FRIGOTTO, I996, p. 91).

Ao exprimirem sua visão de escola como graduandos finalistas, os discentes expressam símbolos e significados de uma escola pautada no embate contrahegemônico (FRIGOTTO, 1996; SACRISTÁN, 1996). Suas experiências, como alunos da escola e como graduandos de um curso de formação de professores de Educação Física, talvez lhes permitam refletir e identificar que o modelo de escola hegemônico atual necessita ser superado para que, de fato, a escola exerça seu papel social de transformação:

Não é passar o conhecimento que já existe, mas fazer com que os alunos já entendam a partir das reflexões, porque, se não é daquela forma, o professor fica falando e a gente vai escutando! Os alunos não criam o hábito de refletir sobre o tema. Acho que precisa um respeito maior ao professor. Eu acho que o professor precisa também buscar maneiras de passar melhor o conteúdo (Entrevista, LUIGI).

Eu vejo que a escola, ela não ensina o que deveria ser ensinado. Não tem aquele papel de formadora de cidadão. Você vai lá, lê um monte de coisas e não tem aquela ponte com a realidade do mundo. As escolas ainda ensinam que o Brasil foi descoberto por acaso. Eu vejo minha prima menor lá decorando, sendo que tá errado. Eles falam que é aquilo e acabou, não fazem aquela ponte com a realidade. Não fazem o papel da escola, só querem saber de competição, de fazer a propaganda da melhor escola, de preparar para o vestibular, mas não estão preocupados em transformar aquele aluno. A intenção é passar o aluno (Entrevista, FLORINDA).

Aqui se apresenta outro deslocamento no imaginário dos discentes. Estes, por meio da formação inicial de professores, identificam a importância da escola para a efetivação de um projeto de transformação social embasado no acesso ao conhecimento e na produção de pensamento crítico sobre as realidades. Ou seja, os futuros docentes, após experimentarem a formação inicial, não compreendem a escola do mesmo modo como a vivenciaram em seus processos de escolarização. Paradoxalmente, perspectivar a escola daquela maneira não garante que os 
docentes produzam práticas pedagógicas críticas ou que sejam bem sucedidos em seus trabalhos como professores nas escolas. Vale lembrar que trabalhar envolve uma arriscada trama de discursos e disposições, o que ultrapassa o simples exercício prescritivo do "como deve ser" ou do "como deveria ser" a realidade. No cotidiano da escola pulsam racionalidades diversas e temporalidades imprevisíveis.

Defendemos a ideia de que a escola deveria fomentar o discurso contrahegemônico sempre por meio de um complexo e ativo movimento de negociação em que as reações e resistências de professores e alunos, como indivíduos ou como grupos, pudessem chegar a provocar a recusa e ineficiência das tendências reprodutoras do processo de socialização, pois utilizam conhecimento social e historicamente construído e condicionado como ferramenta de análise para compreender, além das aparências superficiais do status quo. Não obstante, essa instituição deve se orientar para provocar a organização racional da informação fragmentária recebida e a reconstrução das preconcepções acríticas, formadas pela pressão reprodutora do contexto social, por meio de mecanismos e meios de comunicação cada dia mais poderosos e de influências mais sutis (GENTILI, 1996; FRIGOTTO, 1996; PERÉZ GÓMEZ, I998a; SILVA, 2002).

Vale ressaltar que ao defendermos que a escola fomente tal discurso, temos claro que o discurso não é apenas a construção/abstração de ideias. $\bigcirc$ discurso aqui é entendido como a relação teoria e prática que forma, reforma, conforma e transforma os sujeitos por meio das ações e relações que estes estabelecem, e, por isso mesmo dado o caráter dialógico e dialético do discurso ele também se forma, se reforma, se conforma, se transforma, pois é uma construção social, não individual, sendo que para sua análise é imprescíndível a consideração do contexto histórico-social e das condições em que fora produzido; neste sentido o discurso expressa uma determinada visão de mundo, na qual é imperativo a sua vinculação a do seu autor ou autores, bem como à sociedade em que este(es) viva(m).

que apontamos é que, numa perspectiva crítica, as ações e relações dos sujeitos são orientadas por um dado discurso (normativo), mas não engessado e sim que se alimenta do vivido refletido que se configura como experiência para, pelo mesmo processo, converter-se em saber. Um saber que dê conta de lidar com o estabelecido hegemonicamente, sem deixar de perceber que a realidade do cotidiano escolar é dinâmica, imprevisível, complexa e até mesmo caótica. E há de se considerar também que é preciso ver tais elementos não como meros obstáculos, mas como algo que inevitavelmente teremos de lidar no trabalho docente, uma vez que este é relacional. Destaca-se a necessidade de que tais elementos sejam considerados pelos discentes (futuro docentes) a fim de que possam perceber e/ou construir possibilidades frutíferas e bem-sucedidas na relação ensino-aprendizagem 
que futuramente estabelecerão com seus alunos e, assim, tentar evitar o conformismo e/ou a atribuição de culpa aos outros pelas impossibilidades de realização de um trabalho docente diferente daquele criticado por ele e assentado numa perspectiva crítica e contra-hegemônica. Ou o que é ainda pior: atribuir a culpa a si mesmo por tal impossibilidade/fracasso.

No bojo dessa discussão, afirmamos a superação da perspectiva do professor apenas como "transmissor" de conteúdos, como único detentor dos conhecimentos. A concepção de educação, no processo de ensino entre os professores e alunos, não deve ser totalmente definida previamente; deveria ser vinculada aos problemas da prática social (FREIRE, 1996; PERÉZ GÓMEZ, 1998a; SILVA, 2002).

A pesquisa nos mostra que a "formação inicial" dos professores de Educação Física começa bem antes do ingresso na universidade. Os futuros professores entraram no curso superior com imaginários construídos, principalmente, em seus processos de escolarização que, por vezes, pode funcionar como bloqueio e escudo contra a formação de pensamento crítico. No entanto, tais imaginários também se constituem como uma importante possibilidade de problematização e de devir, por onde possamos nos compreender como docentes em formação sempre imersos em discursos de verdades que necessitam ser, incessantemente, colocados em análise.

\section{CONSIDERAÇÕES FINAIS}

Em suma, a rede de sentidos construídas nos imaginários dos discentes que cursaram a disciplina EFE III parece ter se constituído a partir da amálgama dos símbolos e significados internalizados/apropriados que se imbricam desde as experiências vividas em seu processo de escolarização até suas experiências a respeito da escola como graduandos finalistas de um curso de formação de professores.

Os esquemas apresentados (Esquema I e Esquema 2) não devem ser compreendidos como formas de imaginários, mas como dispositivos que nos auxiliem a pensar em possíveis ligações/relações entre símbolos e significados. Estes podem se constituir como importantes "referências sensíveis" a serem discutidas e problematizadas na formação inicial no escopo de que novas relações com tais símbolos e significados sejam produzidas.

Nesse sentido, tanto a rede de sentidos construída a respeito da escola, quanto àquela referente à Educação Física influenciam no processo de ensinoaprendizagem na formação inicial de professores de Educação Física. Não isentamos, contudo, a própria formação inicial como alimentadora de imaginários resistentes à formação do pensamento crítico, quando essa reforça/repete o modelo escolar 
conteudista e desconectado das realidades escolares nas quais os futuros professores enfrentarão adversidades de infinitas ordens (VASCONCELLOS SILVA, 2007).

Verificamos que não basta, nos cursos de formação inicial, ter como preocupação fundamental apenas a transmissão de conteúdos acadêmicos, já que os alunos até os decoram, produzem bons trabalhos conceituais, mas não têm força para movimentar suas sensibilidades, suas condições estéticas. Portanto, afirmamos que as primeiras e primordiais investidas da formação inicial sejam empregadas no sentido de levar os futuros professores a "desnaturalizar" o mundo, a história e suas próprias histórias como sujeitos, que façam emergir seus processos de escolarização e os problematizem para que outras formas de pensamento sobre a escola, sobre o "ser" professor e sobre aprender e ensinar sejam forjados.

The production of social imaginaries about the school and its effects on the initial formation of physical education teachers

ABSTRACT: It is about the deployment of research made with students whose major is Physical Education. It aims, in an ethnographic work, at understanding and analyzing the social imaginary of such students about their school experiences and initial formation. Through the empirical work discussed regarding the theoretical production about the thematic, as well as the other data that are built throughout the school process of future teachers. Those structures are expressed (with considerable force, certain conformism and conservatism) in the imaginary of the students in the formation process, what creates challenges and possibilities for the process of critical formation of Physical Education teachers working at schools.

KEY WORDS: School Physical Education; social imaginary; schooling; initial formation.

La producción de imaginarios sociales sobre la escuela y sus efectos en la formación inicial de maestros de educación física

RESUMEN: Es el despliegue de una investigación realizada con estudiantes de licenciatura en educación física. Busca, por medio de un estudio etnográfico, comprender y analizar el imaginario social de estos alumnos acerca de sus experiencias escolares y de formación inicial en la docencia. Valiéndose del trabajo empírico problematizado con base en la producción teórica sobre el tema, así como otros datos que posibilitaron triangulaciones, hemos identificado elementos y esquemas que se construyen a lo largo del proceso de escolarización de los futuros docentes. Estas estructuras se expresan (con una fuerza considerable, cierto conformismo y conservadurismo) en el imaginario de los estudiantes en formación, lo que apunta para los retos y posibilidades para el proceso de formación crítica de profesores de educación física para trabajar en la escuela.

PALABRAS CLAVES: Educación física escolar; imaginario social; escolarización; formación inicial. 


\section{REFERÊNCIAS}

ANDRÉ, M. E. D. A. de. Estudo de caso em pesquisa e avaliação educacional. Brasília: Líber Livro Editora, 2005.

. Etnografia da prática escolar. 5. ed. Campinas: Papirus, 1995.

BOGDAN, R.; BIKLEN, S. Investigação qualitativa em educação. uma introdução à teoria e aos métodos. Porto: Porto Editora, 1994.

CASTORIADIS, C. A instituição imaginária da sociedade. Rio de Janeiro: Paz e Terra, 1982.

CAPARRÓZ, F. E. et al. Formação inicial de professores de Educação Física: (re) construindo a prática pedagógica na Disciplina Educação Física escolar III do CEFD-UFES. In: CONGRESSO ESTADUAL DE EDUCAÇÃO FÍSICA E CIÊNCIAS DO ESPORTE/ES, 3., 2006, Linhares - ES. Anais... Linhares: unilinhares, 2006. I CD-ROM. GTT- Formação profissional.

FREIRE, P. Pedagogia da autonomia: saberes necessários à prática educativa. São Paulo: Paz e Terra, 1996.

FRIGOTTO, G. A formação e profissionalização do educador: novos desafios. In: SILVA, T. T. da; GENTILI, P. (Org.). Escola S.A.: quem ganha e quem perde no mercado educacional do neoliberalismo. Brasília: CNTE, 1996, p. 75-104.

GABRIEL O PENSADOR. Estudo errado. Gabriel o pensador: as melhores. [SI] Sony, 1999. I CD Faixa 9.

GENTILI, P. Neoliberalismo e educação: manual do usuário. In: SILVA, T. T. da; GENTILI, P. (Org.). Escola S.A.: quem ganha e quem perde no mercado educacional do neoliberalismo. Brasília: CNTE, 1996, p. 9-49.

KREUSBURG MOLINA, R. M. O enfoque teórico metodológico qualitativo e o estudo de caso: uma reflexão introdutória. In: TRIVIÑOS, A. N. S.; MOLINA NETO, V. (Org.). A pesquisa qualitativa na Educação Física: alternativas metodológicas. Porto Alegre: EDUFRGSSulina, 1999. p. 95-105.

LAVILLE, C.; DIONNE, J. A construção do saber: manual de metodologia da pesquisa em ciências humanas. Porto Alegre: Artmed, 1999.

LEFEBVRE, H. A vida cotidiana no mundo moderno. São Paulo: Ática, 1991.

MACEDO, R. S. A etnopesquisa crítica e multirreferencial nas ciências humanas e na educação. Salvador: EDUFBA, 2000.

PÉREZ GÓMEZ, A. I. As funções sociais da escola: da reprodução à reconstrução crítica do conhecimento e da experiência. In: SACRISTÁN, J. G.; PÉREZ GÓMEZ, A. I. (Org.). Compreender e transformar o ensino. 4. ed. ArtMed, 1998, p. 13-26. 
SACRISTÁN, J. G. Neoliberalismo e educação: manual do usuário. In: SILVA, T. T. da; GENTILI, P. (Org.). Escola S.A.: quem ganha e quem perde no mercado educacional do neoliberalismo. Brasília: CNTE, 1996, p. 50-74.

SILVA, J. I. da. Educação e globalização: o professor e suas relações políticas. In: MUÑOZ PALAFOX, G. H. et al. (Org.). Planejamento coletivo do trabalho pedagógico - PCTP: a experiência de Uberlândia. 2. ed. Uberlândia: Casa do Livro; Linograf, 2002, p. 35-47.

TEVES, N. O imaginário na configuração da realidade social. In: TEVES, N. (Org.). Imaginário social e educação. Rio de Janeiro: Gryphus: Faculdade de Educação da UFRJ, 1992, p. 3-33.

VASCONCELLOS SILVA, B. Imaginário social dos alunos do curso de Educação Física a respeito do processo de ensino-aprendizagem na formação inicial de professores: $O$ caso da disciplina Educação Física escolar III do CEFD-UFES. 2007. Trabalho de Conclusão de Curso. (Licenciatura em Educação Física) - Universidade Federal do Espírito Santo, Espírito Santo, 2007.

Recebido: 20 jul. 2009 Aprovado: 20 jan. 201 I

Endereço para correspondência: Ueberson Ribeiro Almeida Rua Clarício Alves Ribeiro, 22 - Bairro Oriente Cariacica - ES CEP: 29|50-670 